OPEN ACCESS

Edited by:

Sabina Cevoli,

IRCCS Istituto Delle Scienze

Neurologiche di Bologna (ISNB), Italy

Reviewed by:

Marcelo M. Valença,

Federal University of

Pernambuco, Brazil

Roberto De Simone,

University of Naples Federico II, Italy

*Correspondence:

Jeong Wook Park pjw5016@gmail.com

Specialty section:

This article was submitted to Headache Medicine and Facial Pain a section of the journal Frontiers in Neurology

Received: 19 February 2019 Accepted: 14 June 2019 Published: 02 July 2019

Citation:

Kim SH, Kim TW, Shin HE, Lee SB, Ryu DW and Park JW (2019) Are CSF Pressure Factors Related to the Development of Post-dural Puncture

Headache? Front. Neurol. 10:700 doi: 10.3389/fneur.2019.00700

\section{Are CSF Pressure Factors Related to the Development of Post-dural Puncture Headache?}

\author{
Seong Hoon Kim ${ }^{1}$, Tae Won Kim ${ }^{2}$, Hae Eun Shin ${ }^{1}$, Si Baek Lee ${ }^{1}$, Dong Woo Ryu ${ }^{1}$ and \\ Jeong Wook Park ${ }^{1 *}$
}

${ }^{1}$ Department of Neurology, College of Medicine, Uijeongbu St. Mary's Hospital, The Catholic University of Korea, Uijeongbu, South Korea, ${ }^{2}$ Department of Neurology, College of Medicine, Incheon St. Mary's Hospital, The Catholic University of Korea, Incheon, South Korea

Post-dural puncture headache (PDPH) is an unfavorable situation seen in considerable number of patients even though atraumatic and small needle reduces its incidence. CSF pressures measured at the time of puncture change after CSF drainage. In the present study, we investigated relationships between CSF pressure-related factors and occurrence of PDPH. We prospectively enrolled 103 participants who underwent CSF studies for meningitis. Using a standardized protocol, CSF opening pressure (OP) and closing pressure (CP) were measured, and cerebrospinal elastance (ECS) and pressure-volume index (PVI) were investigated. Within 14 days after dural puncture, we confirmed PDPH. According to PDPH development, the CSF pressure factors and clinical variables were compared between PDPH and non-PDPH group. Of the 103 participants, $100(97.0 \%)$ had decreased CP, 16 (15.5\%) had values below $6 \mathrm{cmH}_{2} \mathrm{O}$ and the pressure change after dural puncture (OP-CP) was $6.1 \pm 3.1 \mathrm{cmH}_{2} \mathrm{O}$. PVI and ECS measured by CSF drainage were $99.8 \pm 89.5$ and $0.4 \pm 0.2 \mathrm{cmH}_{2} \mathrm{O} / \mathrm{mL}$. Among the demographic factors, body weight was correlated with OP ( $r=0.27), \mathrm{CP}(r=0.35)$, and PVI $(r=0.20)$. Height was weakly correlated with CP $(r=0.199)$ During the study period, 22 participants (21.34\%) developed PDPH. None of the CSF pressure factors were significantly different between the PDPH and non-PDPH group and did not contributed to the development of PDPH. CSF pressure factors might not be related to the development of PDPH.

Keywords: post dural puncture headache, CSF opening pressure, CSF closing pressure, cerebrospinal elastance, pressure volume index

\section{INTRODUCTION}

Dural puncture is essential for the diagnosis of CNS infections and disorders related to CSF dynamics (1). Post-dural puncture headache (PDPH) occurs in a considerable number of patients and causes difficulties for clinicians. Previous studies reported that the overall prevalence of PDPH was $20-40 \%$ with a conventional method, but smaller size and atraumatic needle could reduce the incidence to $3 \sim 6 \%(1,2)$. In most cases, PDPH occurs within $24-48 \mathrm{~h}$ after dural puncture, and ICHD-3 is defined as a headache within 5 days after CSF drainage (3). PDPH is usually accompanied by neck stiffness and/or subjective hearing symptoms. Even though the majority of 
patients recover spontaneously within 2 weeks, some require treatment with autologous epidural lumbar patches.

Several hypotheses have been presented explaining the pathogenesis of $\mathrm{PDPH}$, such as traction of pain-sensitive structures such as the meninges or cranial nerve occurring when upright and vasodilation to maintain intracranial volume according to the Monro-Kellie doctrine $(4,5)$. Although 7.2.1 PDPH is classified as a subcategory of 7.2, the headache attributed to low CSF pressure in ICHD-3 and low CSF pressure or dry-tapping, which is frequently seen clinically, studies of the role of CSF pressure as a mechanism underlying the development of $\mathrm{PDPH}$ are still inconclusive (6-8). In clinical practice, it is often difficult to repeat dural punctures in order to measure CSF pressure in patients with suspected PDPH.

Along with opening pressure (OP), pressure measured immediately after CSF drainage is referred to as closing pressure (CP). It is plausible to hypothesize that $\mathrm{CP}$, more than OP, reflects the CSF pressure environment at the time of $\mathrm{PDPH}$ generation. Measurements of $\mathrm{CP}$ might be helpful in situations of idiopathic intracranial hypertension (IIH) and hydrocephalus, because the primary purpose of management is reducing pressure through CSF drainage $(9,10)$. In $\mathrm{IIH}$, recurrent dural puncture and checking of CSF pressure have low therapeutic value, but pressure changes associated with CSF drainage provide helpful information for the prognosis of EVD and CSF shunts $(9,11)$.

The change in pressure between $\mathrm{OP}$ and $\mathrm{CP}$ (OP-CP) roughly reflects volume of the CSF reservoir (12). Craniospinal elastance (ECS), which is the change of pressure per change in removed CSF volume $(\Delta \mathrm{P} / \Delta \mathrm{V})$, and the pressure-volume index $(\mathrm{PVI})$, which is the calculated volume required to raise CSF pressure by a factor of 10 , have been used as parameters to predict compliance of the CSF space $(13,14)$. ECS and PVI have been investigated in patients with spontaneous CSF leakage and idiopathic intracranial hypertension $(13,15)$.

In the present study, we investigated whether CSF pressure factors at the time of CSF examination are associated with subsequent development of PDPH.

\section{MATERIALS AND METHODS}

\section{Participants}

This study was conducted prospectively from October 2014 through June 2018. We enrolled participants who were scheduled to undergo CSF studies to detect meningitis.

Before CSF study, all participants were evaluated by brain CT, basic laboratory tests, clinical history, and neurologic examinations. We excluded participants with a history of neurologic disease (including primary and secondary headache disorders and postural headache), connective tissue disorders, previous dural puncture, or abnormal structural lesions on neuroimaging studies. Participants who underwent traumatic tap and failed dural puncture were also excluded. After confirmatory CSF analysis, we enrolled participants with aseptic meningitis or normal CSF findings.

\section{Study Design}

To evaluate the relationship between pressure factors and PDPH, we performed dural puncture while controlling for the following factors related to PDPH. (1) Needle shape: Quincke needle, (2) needle size: 20-23 gauge, (3) bevel orientation: parallel to the long axis of the spine, (4) needle insertion location and angle: L4-5 interspace with 10-degree angle toward the umbilicus, (5) CSF drainage volume: $15 \mathrm{ml}$, (6) dural puncture position: sidelying position, (7) resting duration and hydration after dural puncture: $4 \mathrm{~h}$ and $80 \mathrm{ml} / \mathrm{h}$ with normal saline. Skilled neurologists performed all dural puncture procedures.

Once the CSF flow was established, a stopcock valve and manometer were attached to the spinal needle. To avoid false rises and drops of CSF pressure, we asked participants to relax and straighten their legs slowly. CSF OP was checked at the peak level of the manometer that showed slight up-down changes with respiration. Then, we opened the valve and collected CSF into a test tube. After CSF drainage was complete, we opened the manometer valve and measured CP in the same way.

\section{Diagnosis of PDPH}

According to ICHD-3, the diagnostic criteria of PDPH include a headache that occurs within 5 days after dural puncture as well as criteria for identifying headaches attributed to low CSF pressure. Some previous studies reported that PDPH could develop between 5 and 14 days after dural puncture (7). Therefore, we confirmed the occurrence of PDPH on the fifth and 14th days after dural puncture. We defined PDPH as newly developed orthostatic headache after dural puncture with clearly different characteristics compared to baseline headache features. Orthostatic headache is defined below; when the participant is in the supine position, the headache improves more than $50 \%$ or to VAS score $<3$. When PDPH was suspected, we carefully observed the consistency of headache character for 2 days.

\section{Ethical Approval}

This study was approved by the local ethics committee of Ujeongbu St. Mary's Hospital, Ujeongbu, Republic of Korea (approval no. UC17OESI0075). Written informed consent was obtained from all participants. For participants who were 18 years old or younger, we obtained written informed consent from their parents.

\section{Data Analysis}

When the lumbar puncture procedure ended, the operator checked and described the pressure (OP, CP), procedure (needle size, trial number, drained CSF volume) and demographic factors. The craniospinal elastance (ECS) was calculated using $\mathrm{OP}, \mathrm{CP}$, and removed CSF volume (13).

$$
E C S=\frac{\Delta P}{\Delta V}=\frac{(O P-C P)}{\text { drained volume }}
$$

Pressure-volume index (PVI) is the CSF volume required to raise CSF pressure by a factor of 10 .

$$
P V I=\frac{\Delta V}{\left(\log _{10} \frac{O P}{C P}\right)}=\frac{15}{\left(\log _{10} \frac{O P}{C P}\right)}
$$


The data described in the mean \pm standard deviation. All statistical analyses were performed to test relationships between PDPH and controls using R (version 3.5.1). The Mann-Whitney $U$-test was used for numerical variables. Categorical variables were analyzed by the chi-square test with Fisher's correction when appropriate. According to diagnosis, statistical analysis performed between PDPH and non-PDPH in each aseptic meningitis and normal CSF group. Spearman correlation analysis was used to evaluate the relationships between factors that may be related to $\mathrm{PDPH}$. Binary logistic regression analysis was performed to assess significant related factors for PDPH. All tests were two-tailed with a significance level of $p<0.05$.

\section{RESULTS}

\section{Demographics}

For this study, we enrolled 133 participants who visited our center with diagnoses of meningitis. We excluded 30 participants who did not match inclusion criteria, had incomplete data, or were lost to follow-up. Finally, 103 participants (53 male; age: 33.3 \pm 13.5 years) were included in the analysis (Figure 1). CSF study confirmed aseptic meningitis in 50 participants (48.5\%) and all others (53 participants, 51.5\%) had normal CSF. Final diagnoses are described in Figure 1. PDPH developed in 22 participants $(21.4 \%)$ at $1.91 \pm 1.41$ days after lumbar puncture. We treated 17 of $22(77.27 \%)$ with autologous blood patches, while five $(22.73 \%)$ spontaneously improved with bed rest.

\section{CSF Pressure Factor Analysis}

CSF OP was $16.3 \pm 4.7 \mathrm{cmH}_{2} \mathrm{O}$, and $\mathrm{CP}$ was $10.2 \pm 3.5 \mathrm{cmH}_{2} \mathrm{O}$. After draining CSF, 100 participants (97.1\%) exhibited decreased CSF pressure with decreases of pressure (OP-CP) of $6.1 \pm 3.1$ $\mathrm{cmH}_{2} \mathrm{O}$. CSF CP was lower than $6 \mathrm{mmH}_{2} \mathrm{O}$ in 16 participants (15.5\%) (Figure 2).

CSF OP showed a significant relationship with weight ( $r=0.270, p=0.006)$, and $\mathrm{CP}$ was also significantly correlated with weight $(r=0.347, p<0.001)$ and height $(r=0.199, p=0.047)$. $\Delta$ OP-CP showed a negative relationship with puncture trial number $(r=-0.26, p=0.024)$ and

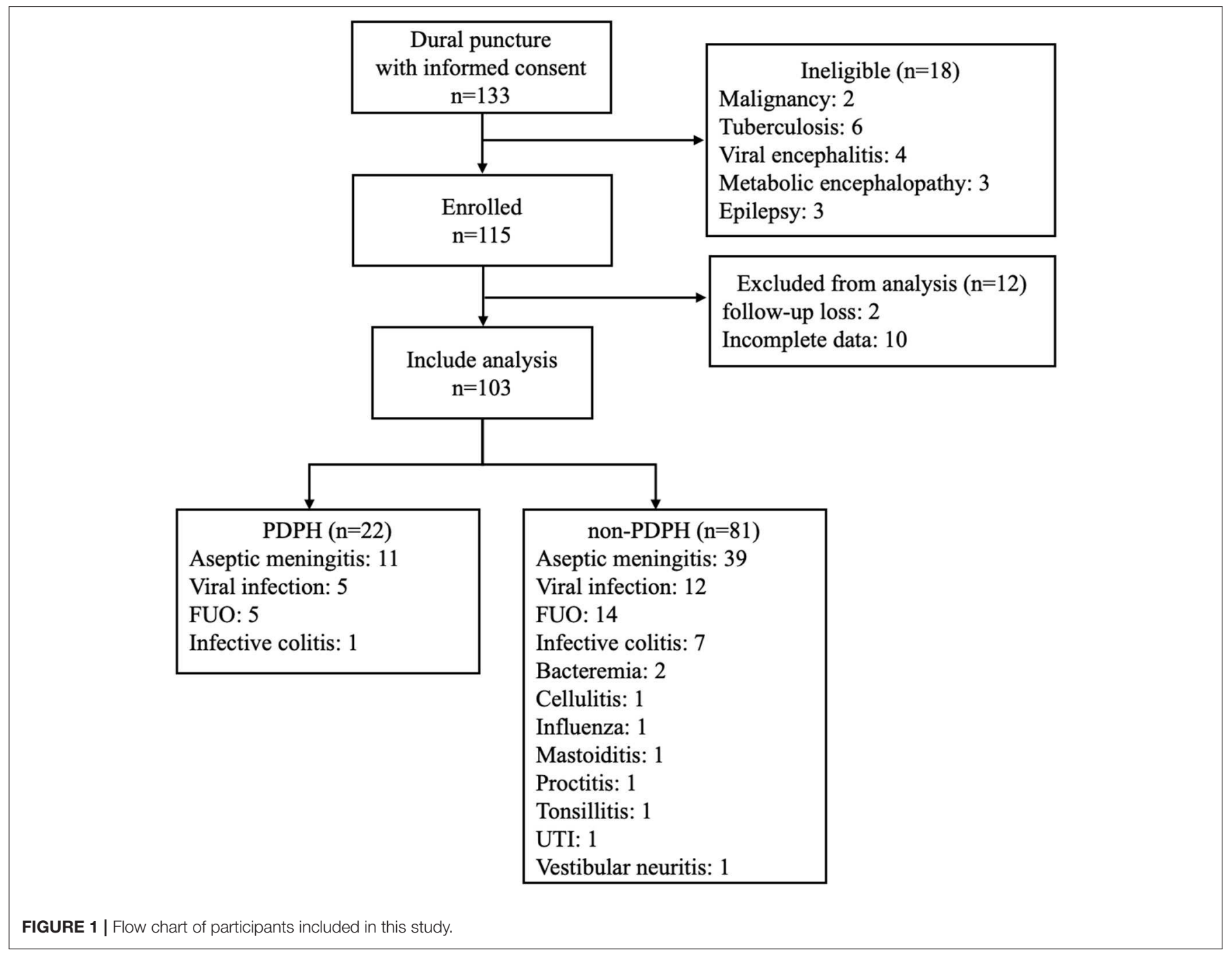




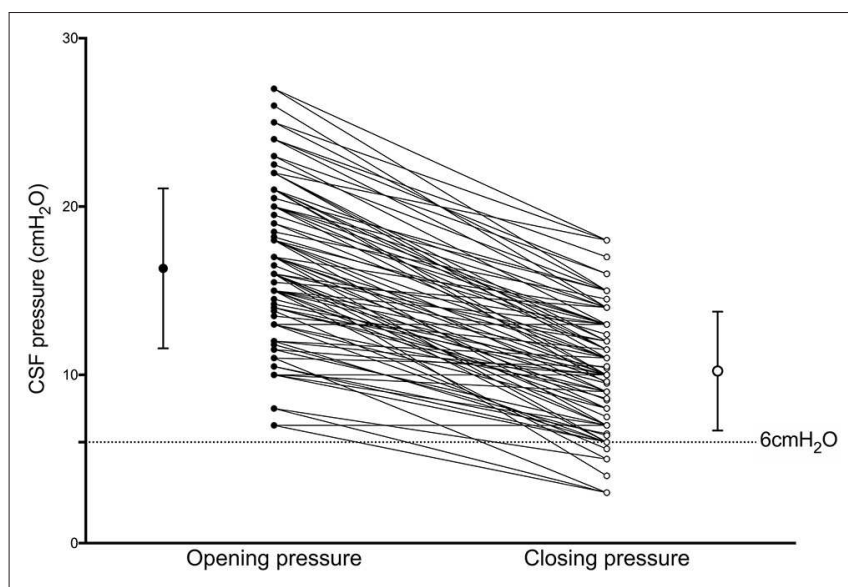

FIGURE 2 | Results of Wilcoxon signed-rank tests between Opening (OP) and Closing (CP) pressure CP is significantly lower than OP $(p<0.001)$. Bars with whiskers indicate mean with standard deviation of OP (closed dot; $16.3 \pm 4.7$ $\mathrm{cmH}_{2} \mathrm{O}$ ) and $\mathrm{CP}$ (open dot; $10.2 \pm 3.5 \mathrm{cmH}_{2} \mathrm{O}$ ).

PVI was significantly correlated with weight $(r=-0.020$, $p=0.046)($ Table 1).

\section{CSF Pressure Factors and PDPH}

All participants were divided into a PDPH group $(n=22)$ and a non-PDPH group $(n=81)$. CSF pressure factors include OP, CP, OP-CP, ECS, and PVI. None of these factors differed between groups (Table 2). Demographic characteristics and other CSF factors did not differ between the two groups. In subgroup analysis after dividing into two groups according to presence of viral meningitis, CSF pressure and procedural factors did not show the difference (Table 3). In bivariate logistic regression analysis, CSF pressure factors were not related to PDPH development (Table 4).

\section{DISCUSSION}

In this study, we detected three significant outcomes. (1) After CSF drainage, CSF CP significantly decreased compared to OP.

(2) Most CSF pressure factors were correlated with body weight.

(3) CSF pressure factors are not related to PDPH development.

Because CSF is confined to a restricted space, it is predictable that the CSF pressure changes after CSF drainage (12). CP has been studied mainly in $\mathrm{IIH}$, with varying results (9). A previous study reported that achieving a decrease of $1 \mathrm{cmH}_{2} \mathrm{O}$ of pressure requires removing $0.91 \mathrm{ml}$ of CSF (9). However, the pressurevolume relationship was not observed at pressures $>15 \mathrm{cmH}_{2} \mathrm{O}$. Another recent study reported that when OP was below 20 $\mathrm{cmH}_{2} \mathrm{O}$, pressure decreased by $0.52 \mathrm{cmH}_{2} \mathrm{O}$ per $1 \mathrm{ml}$ of drainage (13). Structural changes in the elasticity of the CSF lining were related to long-lasting intracranial pressure increments, and this relationship should be considered in such cases. There is no established reference range for CSF CP because it is affected by the volume removed (13). In a previous study, CSF pressure decreased after dural puncture, similar to our findings (6). The
TABLE 1 | Correlations between CSF pressure factors and demographic characteristics.

\begin{tabular}{|c|c|c|c|c|c|c|c|c|}
\hline & Age $S$ & Sex (male) & ) Height & Weight & BMI & Trial & Needle & Volume \\
\hline OP & -0.175 & 0.170 & 0.181 & $0.270^{\star \star}$ & 0.172 & -0.145 & -0.047 & 0.157 \\
\hline $\mathrm{CP}$ & -0.118 & $0.211^{\star}$ & $0.199^{\star}$ & $0.347^{\star \star \star}$ & 0.19 & 0.039 & 0.063 & 0.108 \\
\hline $\mathrm{OP}-\mathrm{CF}$ & $P-0.134$ & 0.013 & -0.036 & 0.028 & 0.041 & $-0.226^{\star}$ & -0.122 & 0.12 \\
\hline ECS & -0.136 & -0.050 & -0.036 & -0.022 & -0.05 & -0.182 & -0.089 & -0.238 \\
\hline PVI & 0.034 & 0.144 & 0.133 & $0.200^{\star}$ & 0.173 & 0.145 & 0.079 & 0.319 \\
\hline
\end{tabular}

Spearman's correlation coefficients are shown $\left(^{*}\right)$ indicates significant values ${ }^{*} P<0.05$; ${ }^{\star \star} P<0.01 ;{ }^{* \star \star} P<0.001$.

strength of present study is that we properly adjusted CSF drainage volume and influencing factors. Our results indicate that an average decrease of $0.4 \pm 0.2 \mathrm{mmH}_{2} \mathrm{O}$ occurs per $1 \mathrm{ml}$ of CSF drained.

Clinically, obesity is related to $\mathrm{IIH}$ and weight gain increases the likelihood of developing IIH $(16,17)$. Women with IIH who lost weight had significantly reduced intracranial pressure and improved clinical symptoms (18). The mechanism underlying the relationship between body weight and intracranial pressure is still unclear, and there is a suggestion that increased intrathoracic and venous pressure due to abdominal mass affects the intracranial pressure by causing it to increase (19). A previous study reported BMI had a small but insignificant influence on CSF pressure in adults (20). Another study reported that CSF pressure increases by $3 \mathrm{cmH}_{2} \mathrm{O}$ for every 10 units of BMI in children (21). The results of the present study suggest that body weight, more than overall obesity as assessed by BMI, affects CSF factors including OP, CP, and PVI.

Younger age, female sex low BMI, history of $\mathrm{PDPH}$, and chronic headache are known as risk factors for the development of PDPH $(6,7)$. Previous studies of CSF CP and PDPH have been inconclusive (6). In our study, CSF $\mathrm{CP}$ was not associated with the development of PDPH. In 16 participants, $\mathrm{CP}$ was lower than $6 \mathrm{cmH}_{2} \mathrm{O}$, which is the diagnostic cutoff for PDPH, but there was no difference between $\mathrm{PDPH}$ and non-PDPH group (22.7\% vs. $13.6 \%, p=0.325)$. We may make several observations about these results. First, CSF pressure evaluations are not performed at the time of $\mathrm{PDPH}$ diagnosis, so restorative changes may occur in CSF pressure over time. Second, when PDPH occurs in a patient without a concomitant significant decrease of $\mathrm{CP}$, we should consider the possibility of additional pressure drop due to persistent CSF leakage at the initial dural puncture point. In $\mathrm{SIH}$ patients, various imaging studies may be used to detect CSF leaks and focal CSF collection (22-24). CSF pressure is significantly lower in PDPH with definite leakage than in cases without leakage (15). Further research may be needed to assess the significance of CSF pressure at the time of PDPH and to analyze its relationship with $\mathrm{CP}$ at the time of initial dural puncture.

We found that decreases in CSF pressure and craniospinal elastance did not affect PDPH development. CSF OP-CP may roughly reflect the CSF reservoir. Large decreases in pressure indicate small reservoirs (12). In patients with 
TABLE 2 | Demographics, CSF variables, and procedural factors in PDPH and non-PDPH groups.

\begin{tabular}{|c|c|c|c|c|}
\hline & $\begin{array}{c}\text { Total } \\
(N=103)\end{array}$ & $\begin{array}{c}\text { PDPH } \\
(N=22)\end{array}$ & $\begin{array}{c}\text { non-PDPH } \\
(N=81)\end{array}$ & $p$-value \\
\hline \multicolumn{5}{|l|}{ DEMOGRAPHICS } \\
\hline Age (years) & $33.3 \pm 13.5$ & $29.5 \pm 10.2$ & $34.3 \pm 14.1$ & 0.133 \\
\hline Sex (male) & $50(48.5 \%)$ & $10(45.5 \%)$ & $40(49.4 \%)$ & 0.931 \\
\hline Height (cm) & $166.5 \pm 8.8$ & $167.1 \pm 9.5$ & $166.3 \pm 8.6$ & 0.710 \\
\hline Weight (kg) & $64.8 \pm 14.0$ & $62.8 \pm 12.8$ & $65.3 \pm 14.3$ & 0.467 \\
\hline BMl & $27.0 \pm 7.5$ & $24.6 \pm 7.2$ & $27.6 \pm 7.5$ & 0.099 \\
\hline \multicolumn{5}{|l|}{ CSF ANALYSIS } \\
\hline Presence of CSF pleocytosis & $50(48.5 \%)$ & $11(50 \%)$ & $39(48.1 \%)$ & 1.000 \\
\hline WBC count $\left(/ \mathrm{mm}^{3}\right)$ & $15.1 \pm 14.2$ & $17.6 \pm 16.1$ & $14.4 \pm 13.7$ & 0.359 \\
\hline Protein (mg/dL) & $61.6 \pm 49.7$ & $53.9 \pm 46.3$ & $63.6 \pm 50.7$ & 0.418 \\
\hline Glucose (mg/dL) & $61.7 \pm 16.2$ & $57.8 \pm 13.3$ & $62.7 \pm 16.8$ & 0.212 \\
\hline \multicolumn{5}{|l|}{ CSF PRESSURE FACTORS } \\
\hline Opening pressure $\left(\mathrm{cmH}_{2} \mathrm{O}\right)$ & $16.3 \pm 4.7$ & $15.1 \pm 4.0$ & $16.7 \pm 4.9$ & 0.16 \\
\hline Closing pressure $\left(\mathrm{cmH}_{2} \mathrm{O}\right)$ & $10.2 \pm 3.5$ & $9.6 \pm 3.5$ & $10.4 \pm 3.5$ & 0.363 \\
\hline $\mathrm{OP}-\mathrm{CP}\left(\mathrm{cmH}_{2} \mathrm{O}\right)$ & $6.1 \pm 3.1$ & $5.4 \pm 2.8$ & $6.3 \pm 3.2$ & 0.263 \\
\hline Craniospinal elastance (ECS; $\Delta \mathrm{P} / \mathrm{mL}$ ) & $0.4 \pm 0.2$ & $0.4 \pm 0.2$ & $0.4 \pm 0.2$ & 0.326 \\
\hline Pressure volume index (PVI) & $99.8 \pm 89.5$ & $107.2 \pm 69.6$ & $97.7 \pm 94.7$ & 0.659 \\
\hline proportion of participants with $\mathrm{CP}<6 \mathrm{cmH}_{2} \mathrm{O}$ & $16(15.5 \%)$ & $5(22.7 \%)$ & $11(13.6 \%)$ & 0.325 \\
\hline \multicolumn{5}{|l|}{ PROCEDURAL FACTORS } \\
\hline Trial number & $2.3 \pm 2.3$ & $2.0 \pm 1.2$ & $2.4 \pm 2.5$ & 0.203 \\
\hline Needle size (gauge) & $21.3 \pm 0.8$ & $21.3 \pm 0.8$ & $21.4 \pm 0.8$ & 0.782 \\
\hline Removed volume (ml) & $15.5 \pm 3.3$ & $15.6 \pm 3.5$ & $15.4 \pm 3.3$ & 0.856 \\
\hline
\end{tabular}

P-values were determined by Mann Whitney-U-tests for numerical variables. Categorical variables were analyzed by chi-square tests with Fisher's correction when appropriate.

TABLE 3 | Subgroup analysis according to diagnosis.

\begin{tabular}{|c|c|c|c|c|c|c|}
\hline & \multicolumn{3}{|c|}{ Aseptic meningitis } & \multicolumn{3}{|c|}{ Normal CSF } \\
\hline \multicolumn{7}{|l|}{ CSF PRESSURE FACTORS } \\
\hline Opening pressure $\left(\mathrm{cmH}_{2} \mathrm{O}\right)$ & $16.0 \pm 3.0$ & $17.3 \pm 4.7$ & 0.395 & $14.1 \pm 4.7$ & $16.1 \pm 5.1$ & 0.250 \\
\hline Closing pressure $\left(\mathrm{cmH}_{2} \mathrm{O}\right)$ & $9.6 \pm 3.7$ & $10.3 \pm 3.6$ & 0.589 & $9.6 \pm 3.5$ & $10.5 \pm 3.5$ & 0.467 \\
\hline Pressure volume index (PVI) & $97.3 \pm 66.2$ & $79.6 \pm 41.2$ & 0.417 & $117.2 \pm 74.7$ & $115.7 \pm 125.6$ & 0.970 \\
\hline proportion of $\mathrm{CP}<6 \mathrm{cmH}_{2} \mathrm{O}$ & $3(27.3 \%)$ & $6(15.4 \%)$ & 0.392 & $2(18.2 \%)$ & $5(11.9 \%)$ & 0.626 \\
\hline \multicolumn{7}{|l|}{ PROCEDURAL FACTORS } \\
\hline Trial number & $2.0 \pm 1.2$ & $2.3 \pm 2.3$ & 0.551 & $1.9 \pm 1.2$ & $2.5 \pm 2.7$ & 0.254 \\
\hline Needle size (gauge) & $21.3 \pm 0.8$ & $21.3 \pm 0.7$ & 0.857 & $21.5 \pm 0.3$ & $21.3 \pm 0.6$ & 0.421 \\
\hline
\end{tabular}

$P$-values were determined by Mann Whitney-U-tests for numerical variables and Fisher's exact tests for categorical variables.

intracranial hypertension, ECS is decreased, and PVI is increased (22). PVI significantly increases in cases of spontaneous intracranial hypotension (SIH) with definite CSF leaks compared to those without CSF leaks (15). Headaches related to CSF leaks are related to decreases of ECS and increases of PVI (22). We hypothesize that these factors may not be directly related to PDPH, but that more complex mechanisms such as vasodilation, pain sensitization, and neuroinflammation are involved in the development of PDPH $(7,19,25)$.

The results of the present study indicate that there is no significant relationship between CSF-related procedures and PDPH. These results are inconsistent with those of previous studies. In most studies, patient posture, operator experience, needle shape, and needle size have been associated with PDPH development $(7,26,27)$. The results of the present 
TABLE 4 | Logistic regression analysis of factors associated with development of PDPH.

\begin{tabular}{|c|c|c|c|c|}
\hline Variables & B & SE & $p$-value & Odds ratio $(95 \% \mathrm{Cl})$ \\
\hline \multicolumn{5}{|l|}{ DEMOGRAPHICS } \\
\hline Age & -0.033 & 0.025 & 0.189 & $0.968(0.918 ; 1.014)$ \\
\hline Sex & -0.350 & 0.917 & 0.703 & $0.705(0.110 ; 4.140)$ \\
\hline Height & 0.015 & 0.056 & 0.783 & $1.016(0.909 ; 1.137)$ \\
\hline Weight & 0.030 & 0.033 & 0.364 & $1.031(0.963 ; 1.099)$ \\
\hline BMl & -0.080 & 0.051 & 0.119 & $0.923(0.827 ; 1.014)$ \\
\hline \multicolumn{5}{|l|}{ CSF ANALYSIS } \\
\hline WBC count & -0.001 & 0.002 & 0.571 & $0.999(0.995 ; 1.002)$ \\
\hline Protein & -0.008 & 0.007 & 0.253 & $0.992(0.976 ; 1.005)$ \\
\hline Glucose & -0.041 & 0.032 & 0.196 & $0.960(0.893 ; 1.006)$ \\
\hline \multicolumn{5}{|c|}{ CSF PRESSURE FACTORS } \\
\hline OP & -0.318 & 0.316 & 0.315 & $0.728(0.398 ; 1.524)$ \\
\hline $\mathrm{CP}$ & 0.178 & 0.328 & 0.586 & $1.195(0.551 ; 2.219)$ \\
\hline $\mathrm{OP}-\mathrm{CP}$ & -0.146 & 0.089 & 0.103 & $0.865(0.720 ; 1.025)$ \\
\hline ECS & -1.807 & 1.257 & 0.151 & $0.164(0.012 ; 1.723)$ \\
\hline PVI & 0.006 & 0.007 & 0.405 & $1.006(0.991 ; 1.021)$ \\
\hline \multicolumn{5}{|c|}{ PROCEDURAL FACTORS } \\
\hline Trial number & -0.207 & 0.176 & 0.239 & $0.813(0.538 ; 1.101)$ \\
\hline Needle size & 0.222 & 0.369 & 0.548 & $1.249(0.623 ; 2.696)$ \\
\hline Removed volume & 0.138 & 0.147 & 0.348 & $1.148(0.851 ; 1.545)$ \\
\hline
\end{tabular}

study require careful interpretation because we adjusted for these factors, which remained constant. The removed CSF volume can non-linearly influence the slope of ECS and PVI change during the drainage time course $(13,15)$. The previous study investigated the pressure-volume changes by using continuous ICP monitoring, but our study did not include monitoring procedure during CSF drainage (15). Because of the limitation of present study design, there is still the possibility that the difference in PCI and ECS depending on presence of $\mathrm{PDPH}$ may not be clarified. Further Investigation may need to reveal the relation between pressure-volume change

\section{REFERENCES}

1. Williams J, Lye DC, Umapathi T. Diagnostic lumbar puncture: minimizing complications. Intern Med J. (2008) 38:587-91. doi: 10.1111/j.1445-5994.2008.01631.x

2. Arevalo-Rodriguez I, Ciapponi A, Roque i Figuls M, Munoz L, Bonfill Cosp X. Posture and fluids for preventing post-dural puncture headache. Cochrane Database Syst Rev. (2016) 3:CD009199. doi: 10.1002/14651858.CD009199.pub3

3. Headache Classification Committee of the International Headache Society (IHS). The International Classification of Headache Disorders, 3rd edition. Cephalalgia. (2018) 38:1-211. doi: 10.1177/03331024177 38202

4. Grant R, Condon B, Hart I, Teasdale GM. Changes in intracranial CSF volume after lumbar puncture and their relationship to post-LP headache. J Neurol Neurosurg Psychiatry. (1991) 54:440-2. doi: 10.1136/jnnp.54.5.440

5. Ghaleb A, Khorasani A, Mangar D. Post-dural puncture headache. Int J Gen Med. (2012) 5:45-51. doi: 10.2147/IJGM.S17834 and CSF removal by using CSF pressure monitoring could be helpful.

This study was conducted in a single institution, and the small number of participants included is a limitation of our study. We included patients with aseptic meningitis, so our results have limitations regarding generalization to other patients for PDPH interpretation. We did not assess intraventricular pressure or establish the presence of definite CSF leaks.

\section{CONCLUSION}

Factors related to CSF pressure might not be related to the development of PDPH.

\section{DATA AVAILABILITY}

All datasets generated for this study are included in the manuscript and/or the supplementary files.

\section{ETHICS STATEMENT}

This study was approved by the local ethics committee of Ujeongbu St. Mary's Hospital, Ujeongbu, Republic of Korea (approval no. UC17OESI0075). Written informed consent was obtained from all participants. For participants who were 18 years old or younger, we obtained written informed consent from their parents.

\section{AUTHOR CONTRIBUTIONS}

SK, HS, SL, DR, TK, and JP conceived and designed the present study. HS, SL, and DR performed dural puncture procedures and acquired data. SK, TK, and JP analyzed and interpreted the data. SK and JP drafted the manuscript and made final decisions regarding the version to be published. JP agreed to be accountable for all aspects of the work and to ensure that questions related to the accuracy or integrity of any part of the work would be appropriately investigated and resolved.

6. Kuntz KM, Kokmen E, Stevens JC, Miller P, Offord KP, Ho MM. Post-lumbar puncture headaches: experience in 501 consecutive procedures. Neurology. (1992) 42:1884-7. doi: 10.1212/WNL.42.10.1884

7. Bezov D, Lipton RB, Ashina S. Post-dural puncture headache: part I diagnosis, epidemiology, etiology, and pathophysiology. Headache. (2010) 50:1144-52. doi: 10.1111/j.1526-4610.2010.01699.x

8. Turnbull DK, Shepherd DB. Post-dural puncture headache: pathogenesis, prevention and treatment. Br J Anaesth. (2003) 91:718-29. doi: 10.1093/bja/aeg231

9. McLaren SH, Monuteaux MC, Delaney AC, Landschaft A, Kimia AA. How much cerebrospinal fluid should we remove prior to measuring a closing pressure? J Child Neurol. (2017) 32:356-9. doi: 10.1177/0883073816681352

10. Graff-Radford SB, Schievink WI. High-pressure headaches, low-pressure syndromes, and CSF leaks: diagnosis and management. Headache. (2014) 54:394-401. doi: 10.1111/head.12283

11. Friedman DI, Liu GT, Digre KB. Revised diagnostic criteria for the pseudotumor cerebri syndrome in adults and children. Neurology. (2013) 81:1159-65. doi: 10.1212/WNL.0b013e3182a55f17 
12. Jurado R, Walker H. Cerebrospinal fluid. In: Walker HK, Hall WD, Hurst JW, editors. Clinical Methods: The History, Physical, and Laboratory Examinations. 3rd ed. Boston, MA: Butterworths (1990). p. 371-82.

13. Griffith B, Capobres T, Patel SC, Marin H, Katramados A, Poisson LM. CSF pressure change in relation to opening pressure and CSF volume removed. AJNR Am J Neuroradiol. (2018) 39:1185-90. doi: 10.3174/ajnr.A5642

14. Marmarou A, Shulman K, LaMorgese J. Compartmental analysis of compliance and outflow resistance of the cerebrospinal fluid system. $J$ Neurosurg. (1975) 43:523-34. doi: 10.3171/jns.1975.43.5.0523

15. Beck J, Fung C, Ulrich CT, Fiechter M, Fichtner J, Mattle HP, et al. Cerebrospinal fluid outflow resistance as a diagnostic marker of spontaneous cerebrospinal fluid leakage. J Neurosurg Spine. (2017) 27:227-34. doi: 10.3171/2017.1.SPINE16548

16. Ko MW, Chang SC, Ridha MA, Ney JJ, Ali TF, Friedman DI, et al. Weight gain and recurrence in idiopathic intracranial hypertension: a case-control study. Neurology. (2011) 76:1564-7. doi: 10.1212/WNL.0b013e3182190f51

17. Daniels AB, Liu GT, Volpe NJ, Galetta SL, Moster ML, Newman NJ, et al. Profiles of obesity, weight gain, and quality of life in idiopathic intracranial hypertension (pseudotumor cerebri). Am J Ophthalmol. (2007) 143:635-41. doi: 10.1016/j.ajo.2006.12.040

18. Sinclair AJ, Burdon MA, Nightingale PG, Ball AK, Good P, Matthews TD, et al. Low energy diet and intracranial pressure in women with idiopathic intracranial hypertension: prospective cohort study. BMJ. (2010) 341:c2701. doi: 10.1136/bmj.c2701

19. Markey KA, Mollan SP, Jensen RH, Sinclair AJ. Understanding idiopathic intracranial hypertension: mechanisms, management, and future directions. Lancet Neurol. (2016) 15:78-91. doi: 10.1016/S1474-4422(15)00298-7

20. Whiteley W, Al-Shahi R, Warlow CP, Zeidler M, Lueck CJ. CSF opening pressure: reference interval and the effect of body mass index. Neurology. (2006) 67:1690-1. doi: 10.1212/01.wnl.0000242704.60275.e9

21. Avery RA. Reference range of cerebrospinal fluid opening pressure in children: historical overview and current data. Neuropediatrics. (2014) 45:206-11. doi: $10.1055 / \mathrm{s}-0034-1376202$
22. Mokri B. Spontaneous low pressure, low CSF volume headaches: spontaneous CSF leaks. Headache. (2013) 53:1034-53. doi: 10.1111/head. 12149

23. Bonetto N, Manara R, Citton V, Cagnin A. Spinal subtraction MRI for diagnosis of epidural leakage in SIH. Neurology. (2011) 77:1873-6. doi: 10.1212/WNL.0b013e318238ee78

24. Sakurai K, Kanoto M, Nakagawa M, Shimohira M, Tokumaru AM, Kameyama M, et al. Dinosaur tail sign: a useful spinal MRI finding indicative of cerebrospinal fluid leakage. Headache. (2017) 57:917-25. doi: 10.1111/head.13075

25. Clark JW, Solomon GD, Senanayake PD, Gallagher C. Substance P concentration and history of headache in relation to postlumbar puncture headache: towards prevention. J Neurol Neurosurg Psychiatry. (1996) 60:6813. doi: $10.1136 /$ jnnp.60.6.681

26. Vallejo MC, Mandell GL, Sabo DP, Ramanathan S. Postdural puncture headache: a randomized comparison of five spinal needles in obstetric patients. Anesth Analg. (2000) 91:916-20. doi: 10.1097/00000539-200010000-00027

27. Waise S, Gannon D. Reducing the incidence of post-dural puncture headache. Clin Med. (2013) 13:32-4. doi: 10.7861/clinmedicine. 13-1-32

Conflict of Interest Statement: The authors declare that the research was conducted in the absence of any commercial or financial relationships that could be construed as a potential conflict of interest.

Copyright (๑) 2019 Kim, Kim, Shin, Lee, Ryu and Park. This is an open-access article distributed under the terms of the Creative Commons Attribution License (CC BY). The use, distribution or reproduction in other forums is permitted, provided the original author(s) and the copyright owner(s) are credited and that the original publication in this journal is cited, in accordance with accepted academic practice. No use, distribution or reproduction is permitted which does not comply with these terms. 